\title{
Una perspectiva británica del partenariado público-privado para la gestión del centro urbano
}

\section{Alan Tallentire *}

Una característica importante y una ventaja de los centros de ciudades grandes y pequeñas es que combinan una gran variedad de usos en un área abarcable y determinada: trabajo, vivienda, comercio, diversión, educación, servicios públicos, sanidad y ocio. Por definición, estas áreas exigen de una gestión específica y su diversidad demanda que ésta sea en cooperación. La respuesta lógica es crear partenariados para la gestión del centro urbano y actualmente existen unos 300 en el Reino Unido.

Las áreas urbanas del Reino Unido representan el 90\% de la población del país, de la producción económica y del empleo. A pesar de los cambios en el empleo, de las pautas residenciales y de las tendencias sociales, las ciudades continúan dominando la infraestructura social. No hay ninguna señal de que las nuevas tendencias, como el comercio electrónico, vayan a erosionar sustancialmente su importancia. De hecho, hay indicios de que las empresas de alta tecnología que impulsan la revolución de Internet pueden necesitar la interacción humana de las ciụdades más que muchas industrias tradicionales.

\section{¿Por qué son importantes los partenariados público-privados en la gestión?}

Sencillamente, para maximizar la variedad de usos en un entorno seguro, accesible y coordinado y, por consiguiente, de una manera eficaz. De la misma manera en que el éxito comer: cial exige un buen plan de negocios, con unos objetivos claros y actuaciones factibles, los centros urbanos extienden esta misma lógica a aquellas zonas donde están operando la mayoría de empresas. Esta actuación se realiza a través de partenariados formados por stakeholders clave (detentadores de intereses, públicos/privados/asociativos, etc.), que van a compartir objetivos, profesionalidad y recursos para crear un plan global apropiado para las necesidades locales y que refuerce los intereses regionales. Este último punto es importante, puesto que existen razones poderosas para creer que las regiones, más que los Estados, se convertirán en el centro del poder económico y de competitividad en el siglo xxI, un hecho que ya está siendo alimentado y reconocido por la tendencia hacia la devolution (descentralización) política en el Reino Unido y en otros lugares.

Un partenariado efectivo y proactivo que refuerza la ciudad, genera consecuentemente la implicación y el sentido de propiedad que atrae tanto a usuarios como a inversores a través de la armonización de sus intereses mutuos. Con cada progreso realizado en este ámbito, los stakebolders y los ciudadanos pueden percibir la diferencia que la gestión del centro urbano representa para ellos. Por tanto:

- Los comerciantes se benefician de un incremento en la cuota de mercado y en el volumen de ventas.

- Los compradores disfrutan de un entorno agradable, seguro y fácilmente accesible, con una amplia selección de comercios y servicios.

- Los visitantes son atraídos por lugares de interés y espectáculos. 
- Los propietarios inmobiliarios se benefician de maximizar sus alquileres e incrementar el valor de la propiedad.

- Las autoridades locales se encuentran con un centro urbano vibrante, viable y que satisface las necesidades de su comunidad.

\section{¿Cuáles son los elementos esenciales?}

El principal objetivo del partenariado para la gestión del centro urbano es desarrollar un entorno próspero y sostenible que implique y beneficie a todos los stakebolders. Es decir, tiene implicaciones para todos los niveles de la sociedad, valorando y animando las contribuciones de aquellos que normalmente son menos capaces de influir en los acontecimientos, tanto de abajo arriba como de arriba abajo. Persigue:

- Promocionar la vida de los centros urbanos, tanto para los inversores como para los ciudadanos.

- Mejorar la gestión del espacio público, para que las ciudades sean seguras y accesibles para todos.

- Ayudar a las ciudades y regiones a comprender, desarrollar, conseguir y retener una ventaja competitiva.

- Crear una visión compartida de la ciudad: su identidad, función, de su posicionamiento con respecto a otras ciudades, e imagen que satisfaga las necesidades de la gente a la que sirve en el presente y en el futuro - ésta es una función cada vez más importante en relación al crecimiento de la economía global y la fuerte competencia interregional que ejercen los atractivos de fuera de la ciudad.

- Mantener una cooperación de apoyo mutuo, y eficaz entre los negocios, el comercio, los minoristas, los propietarios, los prestadores de servicios, el gobierno local, la acción de la comunidad y sus diversos organismos representativos como las cámaras de comercio y las pequeñas agencias comerciales, cuyos intereses compartidos están cubiertos a través de la creación de centros urbanos fuertes, vibrantes y socialmente integradores.

- Crear un plan de trabajo efectivo y un plan de actuaciones implementables anualmente, así como que incluya proyectos a medio y largo plazo que sean apoyados y financiados por todas las partes, centrándose en la mejora del entorno, los accesos, aparcamientos, señalética, seguridad, inversión interna, marketing, atención al cliente y ocio.

- Justificar el apoyo público comunicando y atendiendo las decisiones de manera transparente y objetiva, y, lo que es más importante, promover la confianza publicitando los logros obtenidos.

\section{¿Cuál es el modelo de gestión?}

La gestión del centro urbano reconoce que cada centro urbano es único, y, por tanto, fomenta las soluciones locales basadas en elementos que se han probado como esenciales para todos los actores. Esta filosofía permite que la gestión de los partenariados se construya en torno a los grupos de personas más apropiadas y valiosas. En el Reino Unido, las distintas iniciativas de gestión del centro urbano varían en su organización y encontramos desde partenariados creados ad boc, a sociedades con responsabilidad limitada. Por lo general, están dirigidos por un grupo central de unas diez personas que definen las funciones y responsabilidades de cada una de las partes. Este grupo central denominado con frecuencia «Management Board» (junta) o «Steering Group» (grupo locomotora), desarrolla la estrategia y asegura la continuidad. Opera además, normalmente, a través de un gerente de centro urbano, designado una vez que el grupo ha desarrollado su visión para el centro urbano, con objeto de acomodar las habilidades profesionales y formativas del gerente a las exigencias del plan de trabajo y al programa de proyectos, más que a la inversa.

Los partenariados establecen normalmente subcomités o grupos de trabajo para supervisar áreas genéricas de actividad, proyectos concretos y para desarrollar investigación detallada en temas específicos. Los grupos de trabajo responden ante el grupo directivo. Con frecuencia estos grupos incluyen al gerente de centro urbano o a un miembro de la junta para asegurar una coherencia en el enfoque. El grupo directivo se comunica y celebra reuniones abiertas para permitir que los stakebolders y los usuarios de la ciudad revisen el progreso y examinen los planes futuros, de forma que da a los miembros de la comunidad una oportunidad para manifestar sus puntos de vista.

\section{¿Quién está implicado en la gestión?}

El centro urbano es una ubicación competitiva y los sectores público y privado tienen un mismo interés en su prosperidad: el sector privado por razones de inversión y el sector público por la necesidad de un entorno que sea valorado por todos los sectores de la comunidad. Los partenariados de centros urbanos, trabajan, por tanto, permitiendo que todas las partes interesadas consigan sus objetivos de manera que beneficie a la totalidad. Este enfoque anima a los socios a cooperar, compartiendo sus habilidades de gestión, comerciales, sociales y 
medioambientales para conseguir que el centro urbano resulte tan vital como sea posible.

Los partenariados efectivos reconocen que los stakeholders de la ciudad no se limitan al gobierno local y a los pequeños comerciantes, sino que incluyen la hostelería, operadores de ocio, gerentes de oficinas, proveedores de transporte, inversores y propietarios de solares, así como a los profesionales (como abogados, contables, etc.) y a aquellos que proporcionan servicios (financieros, de policía, educación y sanidad). Los sectores comunitarios y del voluntariado juegan también un papel importante, ofreciendo ayuda para mejorar la vitalidad del centro urbano y proporcionando una perspectiva importante de las necesidades de grupos específicos de usuarios, como las personas minusválidas.

\section{¿Quién paga esta gestión?}

Existen actualmente varias fuentes de ingresos, siendo la más importante las contribuciones voluntarias de los sectores público y privado aunque los partenariados encuentran cada vez más formas novedosas de generar ingresos a partir de la provisión de bienes y servicios. Los diferentes patrocinadores proporcionan, con frecuencia, recursos de formas diferentes, incluyendo dinero para la financiación básica de servicios, bienes o servicios en especie, cesión de recursos humanos en comisión de servicios, patrocinio de acontecimientos o el uso de la influencia. La financiación del sector público puede provenir de programas de subvenciones ya existentes o del propio gobierno local proporcionando fondos de otras partidas relevantes para el centro urbano. Es necesario que el gerente de centro urbano comunique claramente los objetivos de su gestión a los departamentos del gobierno local si se va a utilizar eficientemente esta última fuente de financiación, en particular, sugiriendo modos para que las tareas del gobierno local sean realizadas de manera más efectiva, o identificando dinero público que no ha sido gastado.

La financiación proveniente del sector privado depende de saber identificar correctamente la amplia gama de agendas empresariales y cómo éstas se relacionan con los temas de gestión del centro urbano. Acontecimientos como la rehabilitación de negocios, la expansión y la reubicación pueden ser relevantes cada uno de forma diferente, particularmente si la gestión del centro urbano puede demostrar que la financiación privada pue- de contribuir a incrementar beneficios o reducir costes. Es difícil llegar a transmitir el énfasis suficiente sobre la importancia de que la gestión del centro urbano comprenda los objetivos de los stakebolders a corto, medio y largo plazo.

\section{¿Quién financiará la gestión en el futuro?}

La búsqueda de fuentes de financiación sostenible ha sido siempre un elemento fundamental en la práctica de la gestión del centro urbano, y posiblemente su característica fundamental. A lo largo de los años, la Association for Town Centre Management (UK) y sus miembros han consagrado cantidades ingentes de tiempo y dinero a la búsqueda y a la política de generación de ingresos, tanto a nivel del gobierno nacional como a través de actividades de recaudación de fondos empresariales en ciudades de todo el país.

La ATCM ha defendido durante largo tiempo la necesidad de una estructura que involucre al sector privado en su totalidad, más que confiar en la previsión del gobierno local, y el interés propio de unos pocos empresarios. La práctica actual de aportaciones voluntarias se considera de forma generalizada, correctamente a nuestro entender, que no es sostenible ni equitativa. El gobierno del Reino Unido ha manifestado recientemente su determinación, que nosotros consideramos apropiada, de identificar una forma de involucrar a las empresas en una solución duradera.

En la obra Step Change - Town Centre Management Strategies, Regional Development Agencies and Europe- The Case for a Town Imprevement Zone Programme, publicamos el caso del equivalente británico del programa Business Improvement District americano -que permitiría la existencia de legislación que creara contribuciones locales obligatorias finalistas, destinadas a un plan específico de trabajo, si éste recibiera un apoyo mayoritario-, y donde también se introducen sugerencias específicas para un proyecto piloto. Creemos que la tendencia tanto en el sector público como en el privado y en la política coinciden ahora para hacer que esta propuesta sea el próximo paso lógico. La ATCM ha ofrecido ampliar su investigación actual a modelos de financiación sostenibles para desarrollar el proceso por el cual puede ser implementado el concepto de BID, empleando financiación pública para una serie de experiencias piloto en áreas específicas. 
Traducción de Elisa Romero Sebastín.

* Presidente \& Director General de la Association of Town Centre Management

(ATCM) y Co-Presidente de European Federation of Town Centres (EFTC). 